\title{
A retrospective cohort study of risk factors for missing preschool booster immunisation
}

\author{
Meirion R Evans, Daniel Rh Thomas
}

\begin{abstract}
Aim-To identify factors associated with non-uptake of preschool booster immunisation.

Design-Data from the computerised child health system was used to study all children born in 1990 and living in South Glamorgan, Wales, on their 5th birthday. Factors associated with preschool booster uptake were investigated using multiple logistic regression.

Results-Preschool booster coverage in the study cohort was $91.4 \%$. After adjustment for other variables, uptake was associated most strongly with completed primary immunisation for diphtheria, tetanus, and polio vaccine or first dose measles, mumps, and rubella vaccine. Identifying children who miss either of these predicts $52.4 \%$ of those who miss the preschool booster.

Conclusion-Effective targeting of children who have missed previous immunisations could improve preschool booster uptake and ensure maximum uptake of at least one dose of measles, mumps, and rubella vaccine. Achieving optimum measles vaccine coverage is vital to achieve the goal of measles elimination.

(Arch Dis Child 1998;79:141-144)
\end{abstract}

Keywords: immunisation; diphtheria-tetanus vaccine; measles, mumps, rubella vaccine; patient acceptance of health care

The UK government intends to eliminate indigenous measles by the year 2000. ${ }^{12}$ As part of its strategy, a second dose of measles, mumps, and rubella vaccine was introduced in October 1996 to be given together with the existing preschool booster of diphtheria, tetanus, and polio immunisation (at 3-5 years of age). ${ }^{3}$ High coverage is vital to ensure the success of the new two dose schedule. The aim of the two dose schedule is to achieve immunity in the $5-10 \%$ of children who fail to respond to a single dose. It also provides a second opportunity to immunise children who missed out on the first measles, mumps, and rubella vaccine dose (at $12-15$ months of age). ${ }^{3}$ The introduction of the new dose follows on from the 1994 nationwide school immunisation campaign in which all children from 5 to 16 years of age were offered measles and rubella immunisation to avert a predicted measles epidemic in early $1995 .{ }^{14}$

Uniform coverage of around $95 \%$ with a $100 \%$ effective vaccine is likely to be required to eliminate measles in a stable population. ${ }^{5} \mathrm{~A}$ two dose schedule will achieve virtually $100 \%$ protection, ${ }^{6}$ but current first dose measles, mumps, and rubella coverage is only $90.5 \%$ and falling. ${ }^{7}$ Furthermore, children who fail to receive the first dose of measles, mumps, and rubella vaccine might be more likely to miss preschool booster immunisation. ${ }^{8}$ To ensure the success of the new two dose schedule it will be important to target those children most at risk of missing the second dose. We studied the risk factors associated most closely with missing out on preschool booster immunisation.

\section{Subjects and methods}

STUDY POPULATION

Data were obtained from the computerised child health system ${ }^{9}$ in December 1996 on all children born in 1990 and living in the county of South Glamorgan, Wales, in 1995. The cohort included both children born in the county and those born elsewhere who had moved into the county before their 5th birthday.

\section{OUTCOME AND PREDICTOR VARIABLES}

Uptake of preschool booster immunisation was calculated as the percentage of children who had been immunised by their 5th birthday. Primary immunisation was considered complete if a child had received the full course of three doses of diphtheria (used also as a marker for tetanus and polio uptake) and pertussis. Electoral ward of residence was determined on the basis of each child's postcode.

All potential factors thought to be associated with preschool booster uptake and for which data were available from the child health system were investigated: (1) child sex-boy or girl; (2) birth weight-grouped into $\geqslant 2500 \mathrm{~g}$ (normal birth weight) and $<2500 \mathrm{~g}$ (low birth weight); (3) ethnic group-white or other; (4) type of family - two parent or one parent; (5) maternal age at birth of child-grouped into $<20$ years, $20-29$ years, $30-39$ years, and $\geqslant 40$ years; (6) type of resident-continuous (living in the study district since birth) or moved in (moved into the study district since birth); (7) type of area of residence-categorised geographically by first half of postcode into predominantly rural or predominantly urban; (8) area deprivation score-electoral ward of residence categorised by Jarman underprivileged area score $^{10}$ into low deprivation ward (Jarman score $<0$ ) or high deprivation ward (Jarman score $\geqslant 0$ ); (9) immunisation location-registered for immunisation at a general practice surgery or at a community child health clinic; (10) diphtheria immunisation status (D3) - received (or did not receive) 
Table 1 Influence of child characteristics on preschool booster immunisation uptake in 5 year old children living in South Glamorgan born in $1990(n=6184)$

\begin{tabular}{|c|c|c|c|}
\hline \multirow[b]{2}{*}{ Factor } & \multirow[b]{2}{*}{ Uptake } & \multicolumn{2}{|l|}{ Odds ratio $(95 \%$ CI) } \\
\hline & & Crude & Adjusted ${ }^{\star}$ \\
\hline \multicolumn{4}{|l|}{ Sex } \\
\hline Female & $2742 / 3013$ & 1.00 & 1.00 \\
\hline Male & $2908 / 3171$ & $1.09(0.92$ to 1.31$)$ & $0.99(0.71$ to 1.38$)$ \\
\hline \multicolumn{4}{|l|}{ Birth weight } \\
\hline$<2500 \mathrm{~g}$ & $273 / 288$ & 1.00 & 1.00 \\
\hline$\geqslant 2500 \mathrm{~g}$ & $4554 / 4794$ & $1.04(0.61$ to 1.78$)$ & $1.29(0.68$ to 2.45$)$ \\
\hline \multicolumn{4}{|l|}{ Ethnic group } \\
\hline White & $3647 / 3829$ & 1.00 & 1.00 \\
\hline Other & $237 / 259$ & $0.54(0.34$ to 0.85$)$ & $1.11(0.55$ to 2.25$)$ \\
\hline \multicolumn{4}{|c|}{ Maternal age (years) } \\
\hline$<20$ & $449 / 481$ & 1.00 & 1.00 \\
\hline $20-29$ & $2865 / 3011$ & $1.40(0.94$ to 2.08$)$ & $1.21(0.71$ to 2.07$)$ \\
\hline $30-39$ & $1438 / 1508$ & $1.46(0.95$ to 2.25$)$ & $1.22(0.67$ to 2.24$)$ \\
\hline$\geqslant 40$ & $50 / 56$ & $0.59(0.23$ to 1.49$)$ & $0.48(0.15$ to 1.53$)$ \\
\hline \multicolumn{4}{|c|}{ One parent family } \\
\hline No & $3358 / 3518$ & 1.00 & 1.00 \\
\hline Yes & $1461 / 1556$ & $0.73(0.56$ to 0.95$)$ & $0.73(0.50$ to 1.06$)$ \\
\hline \multicolumn{4}{|c|}{ Type of resident } \\
\hline Continuous & $4647 / 4859$ & 1.00 & 1.00 \\
\hline Moved in & $1003 / 1325$ & $0.14(0.12$ to 0.17$)$ & $0.18(0.11$ to 0.30$)$ \\
\hline \multicolumn{4}{|c|}{ Area of residence } \\
\hline Rural & $580 / 613$ & 1.00 & 1.00 \\
\hline Urban & $4685 / 5029$ & $0.77(0.54$ to 1.12$)$ & $0.72(0.35$ to 1.46$)$ \\
\hline \multicolumn{4}{|c|}{ Area deprivation score (Jarman) } \\
\hline$<0$ & $1655 / 1757$ & 1.00 & 1.00 \\
\hline$\geqslant 0$ & $3572 / 3839$ & $0.82(0.65$ to 1.04$)$ & $1.05(0.71$ to 1.55$)$ \\
\hline
\end{tabular}

^Odds ratios calculated after adjusting for all other variables.

Table 2 Influence of location of immunisation and immunisation history on preschool booster immunisation uptake in 5 year old children living in South Glamorgan born in $1990(n=6184)$

\begin{tabular}{|c|c|c|c|}
\hline \multirow[b]{2}{*}{ Factor } & \multirow[b]{2}{*}{ Uptake } & \multicolumn{2}{|l|}{ Odds ratio $(95 \%$ CI) } \\
\hline & & Crude & Adjusted ${ }^{\star}$ \\
\hline \multicolumn{4}{|c|}{ Location of immunisation } \\
\hline GPs office & $5106 / 5350$ & 1.00 & 1.00 \\
\hline Health clinic & $414 / 499$ & $0.23(0.18$ to 0.30$)$ & $0.64(0.35$ to 1.19$)$ \\
\hline \multicolumn{4}{|c|}{ Had diphtheria (D3) immunisation } \\
\hline No & $28 / 256$ & 1.00 & 1.00 \\
\hline Yes & $5622 / 5928$ & 149.61 (99.38 to 225.20$)$ & 17.09 (5.88 to 49.63$)$ \\
\hline \multicolumn{4}{|c|}{ Had pertussis (P3) immunisation } \\
\hline No & $507 / 781$ & 1.00 & 1.00 \\
\hline Yes & $5143 / 5403$ & $10.69(8.82$ to 12.96$)$ & $2.00(1.17$ to 3.40$)$ \\
\hline \multicolumn{4}{|c|}{ Had measles, mumps, and rubella immunisation } \\
\hline No & $98 / 359$ & 1.00 & 1.00 \\
\hline Yes & $5552 / 5825$ & $54.16(41.67$ to 70.39$)$ & $10.02(5.22$ to 19.22$)$ \\
\hline
\end{tabular}

* Odds ratios calculated after adjusting for all other factors in this table and for all variables in table 1 .

the complete three dose primary diphtheria, tetanus, and polio immunisation course; (11) pertussis immunisation status (P3) - received (or did not receive) the complete three dose primary pertussis immunisation course; (12) measles, mumps, and rubella immunisation status (MMR) - received (or did not receive) a single dose of measles, mumps, and rubella immunisation.

DATA ANALYSIS

Associations between preschool booster immunisation and each of the predictor variables were examined first by univariate logistic regression. For binary variables, unadjusted odds ratios with 95\% confidence intervals (CIs) were calculated and for categorical variables, stratum specific odds ratios with $95 \%$ CIs were calculated. In the multivariate analysis, associations between preschool booster immunisation and all the predictor variables were examined by multiple logistic regression. Predictor variables were categorised into child characteristics, location of immunisation, and primary immunisation status. Odds ratios for

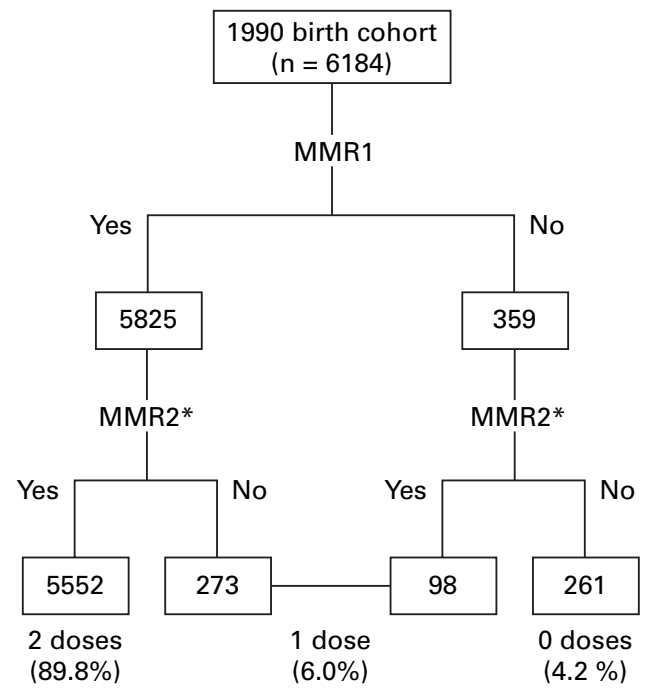

Figure 1 Predicted uptake of measles, mumps, and rubella vaccine in 5 year old children living in South Glamorgan born in 1990. MMR1, measles, mumps, and rubella vaccine first dose; $M M R 2$, measles, mumps, and rubella vaccine second dose. ${ }^{\star}$ Assuming all children who attended for preschool booster would also have received MMR2.

child characteristics were calculated after adjusting for all other child characteristics only. Associations with location of immunisation and primary immunisation status were examined by adjusting for all other variables. Analysis was performed using Stata for Windows, version $4 .{ }^{11}$

\section{Results}

There were 6184 children in the birth cohort and preschool booster immunisation coverage was $91.4 \%$. Immunisation uptake was associated significantly with ethnic group, lone parent family status, and type of resident (continuous or moved in) but not with the child's sex or birth weight (table 1). Ethnic group lost its significance after adjustment for other child characteristics (adjusted odds ratio, 1.11;95\% CI, 0.55 to 2.25 ), but the association with lone parent status was only partly explained by confounding (adjusted odds ratio, 0.73; 95\% CI 0.50 to 1.06 ). Children who had moved into the district were significantly less likely to have had their preschool booster than those who were continuously resident, even after adjusting for other variables (adjusted odds ratio, $0.18 ; 95 \%$ CI, 0.11 to 0.30). Booster uptake was lower among children living in urban areas or in more deprived electoral wards, but this relation disappeared in the multivariate analysis.

After adjusting for all other variables, preschool booster uptake was associated most strongly with a history of previous mumps, measles, and rubella immunisation (adjusted odds ratio, $10.02 ; 95 \% \mathrm{CI}, 5.22$ to 19.22 ) or a history of a completed diphtheria, tetanus, and polio primary course (adjusted odds ratio 17.09; $95 \%$ CI, 5.88 to 49.63 ) (table 2). In contrast, only a weak association with pertussis immunisation status remained (adjusted odds ratio, $2.00 ; 95 \% \mathrm{CI}, 1.17$ to 3.40 ).

More than half $(52.4 \%)$ of the children who missed their preschool booster immunisation 
had either missed their first dose of measles, mumps, and rubella vaccine $(48.9 \%)$ or failed to complete their diphtheria, tetanus, and polio primary course $(42.7 \%)$. The negative predictive value of previous measles, mumps, and rubella immunisation for preschool booster immunisation uptake was $72.7 \%$ and the negative predictive value of a completed diphtheria, tetanus, and polio primary course was $89.1 \%$. In effect, children who missed their first measles vaccine dose were among those most likely to miss the preschool measles dose. If we assume that all children who attended for preschool booster immunisation would also have received a second measles, mumps, and rubella vaccine dose, then $4.2 \%$ of the cohort would remain unimmunised against measles and a further $6.0 \%$ would only have had a single measles vaccine dose (fig 1 ).

\section{Discussion}

The most important risk factor for missing preschool booster immunisation was failure to complete primary immunisation including the first measles, mumps, and rubella immunisation dose. This association was independent of child characteristics or immunisation location. Interestingly, identifying children who missed pertussis immunisation was of much less predictive value, presumably because this reflects parental refusal of pertussis vaccine rather than failure to attend for immunisation. Children of one parent families and children who had moved into the district since birth were also more likely to miss preschool booster immunisation, but other child characteristics had little influence on uptake.

The main limitation of this study is that it relies on the accuracy of data held on the computerised child health system. ${ }^{9}$ Denominator data is likely to be very robust because it is based on birth notification (for children continuously resident in the district) and on tracking by the primary health care team and family health register of children who move in or out of the district. However, records might be missing for some highly mobile children not registered with a GP. Completeness of numerator data is dependent on accurate reporting by GPs and community health doctors of all immunisations given. Immunisation sessions in over $95 \%$ of general practices in South Glamorgan are scheduled by the child health computer system, which ensures comprehensive data collection for all scheduled immunisations. There are also good supplementary systems for collecting data from nonparticipating practices and data on unscheduled immunisations. Finally, child health computer data are also used to validate claims for immunisation target payments made by general practices, which thus have a vested interest in ensuring their accuracy and completeness.

Data on children who have moved into the area are much less complete than data on continuously resident children, particularly data on child characteristics. This might account, at least in part, for the observation that children who had moved in were less likely to receive preschool booster immunisation. However, the

\section{Key messages}

- High uptake of the new second measles, mumps, and rubella vaccine dose is crucial to achieving measles elimination in the UK

- Factors influencing uptake of existing preschool booster immunisation are a useful proxy for anticipated uptake of the second measles, mumps, and rubella dose

- Preschool booster immunisation uptake is associated most strongly with completed primary immunisation with diphtheria, tetanus, and polio or measles, mumps, and rubella vaccines

- Targeting children who have missed either of these primary immunisations will identify about half of all children at risk of missing the second measles, mumps, and rubella dose

association between primary immunisation status and preschool booster uptake remained, even after controlling for this variable.

Although this is the first study of risk factors for missing preschool booster immunisation, numerous risk factors for missing primary immunisation have been described in previous studies. ${ }^{12-18}$ These include parental attitude, ${ }^{13}{ }^{14}$ birth order, ${ }^{14-1618}$ family size, ${ }^{12} 1317$ lone parent status, ${ }^{121516}$ mobility, ${ }^{15}$ immunisation location, ${ }^{16}{ }^{19}$ level of professional knowledge, ${ }^{1314}$ and district deprivation score. ${ }^{12} 1516$ Having a mother who smokes and being third or later in birth order are risk factors for failing to complete a full course of immunisation against Haemophilus influenzae type $b$ (given at 2, 3, and 4 months of age simultaneously with diphtheria, pertussis, tetanus, and polio immunisations). ${ }^{18}$ Uptake of the first measles, mumps, and rubella dose (given at 12 to 15 months of age) is influenced most strongly by primary immunisation status, although there is also an association with birth order, family size, one parent family, and location of immunisation. ${ }^{16}{ }^{17}$ General practices achieve better immunisation rates than community health clinics probably because general practices are rewarded for achieving immunisation targets, ${ }^{19}$ and because of better communication between the practice team and the family. ${ }^{13}$

About half of the children at risk of missing preschool booster immunisation could be targeted by identifying children who have failed to complete primary diphtheria, tetanus, and polio immunisation or who have missed the first measles, mumps, and rubella dose. Obtaining this information should be easy, because the data are available either from the general practice records or the local child health computer system. Reaching these children is more difficult, because they are likely to be from mobile or socioeconomically disadvantaged families. These families might need extra support from the health visitor or practice nurse. Flexibility and accessibility of 
immunisation sessions will need to be considered and opportunistic or domiciliary immunisation strategies might have an important role. ${ }^{1320} 21$ These children could also be targeted by the school health service at the time of school entry. ${ }^{22} 23$

The introduction of the second measles, mumps, and rubella dose to be given alongside the preschool booster provides a second opportunity to ensure that children have had at least one measles vaccine dose. Predicted 90\% uptake for two measles vaccine doses (fig 1) presumes that all children attending for the diphtheria-tetanus preschool booster also receive measles, mumps, and rubella vaccine. However, recent parental concerns about the safety of the measles, mumps, and rubella vaccine mean that comparable coverage to the diphtheria-tetanus booster cannot be taken for granted. Achieving high measles immunisation coverage in this age group is now vitally important. $^{28}$ The successful elimination of measles in the UK depends on it.

We thank $\mathrm{Mr} \mathrm{N}$ Wilton of the child health support team at Health Solutions Wales for providing the immunisation data and $\mathrm{Mr} \mathrm{N}$ Moss of Bro Taf Health Authority for assistance with allocating area deprivation scores.

1 Miller E. The new measles campaign. BMF 1994;309:11023.

2 United Kingdom Health Departments. Immunisation against infectious disease. London: HMSO, 1996.

3 Chief Medical Officers. Change to the routine pre-school booster immunisation programme. London: HMSO, 1996. $\mathrm{CMO}(96) 12$

4 Ramsay M, Gay N, Miller E, et al. The epidemiology of measles in England and Wales: rationale for the national
vaccination campaign. Commun Dis Rep CDR Rev 1994;4: R141-4.

5 Tulchinsky TH, Ginsberg GM, Abed Y, Angeles MT, Akukwe C, Bonn J. Measles control in developing and developed countries: the case for a two dose policy. Bull WHO 1993;71:93-103.
6 Erdman DD, Heath JL, Watson JC, Markowitz LE, Bellini WJ. Immunoglobulin $M$ antibody response to measles virus following primary and secondary vaccination and natural virus infection. $f$ Med Virol 1994;41:44-8.

7 Anon. COVER/Körner: October to December 1997. Vaccine coverage statistics for children up to two years of age in the United Kingdom. Commun Dis Rep CDR Weekly 1998;8:116.

8 Evans MR. Children who miss immunisation: implications for eliminating measles. BMF 1995;310:1367-8.

9 Child Health Computing Committee. A user guide to the child health system statistics package. Cardiff: Welsh Health Common Services Agency, 1989.

10 Jarman B. Identification of underprivileged areas. BMf 1983;286:1704-9.

11 Stata Corporation. Stata statistical software: release 4.0 College Station, Texas: Stata Corporation, 1995.

12 Jarman B, Bosanquet N, Rice P, Dollimore N, Leese B. Uptake of immunisation in district health authorities in England. BMF 1988;296:1775-8.

13 Peckham C, Bedford H, Seturia Y, Ades A. The Peckham report - national immunisation study: factors influencing immunisation uptake in childhood. London: Action for the Crippled Child, 1989.

14 New SJ, Senior ML. 'I don't believe in needles': qualitative aspects of a study into the uptake of infant immunisation in two English health authorities. Soc Sci Med 1991;33:50918.

15 Pearson M, Makowiecka K, Gregg J, Woollard J, Rogers M, West C. Primary immunisations in Liverpool. II: Is there a gap between consent and completion? Arch Dis Child 1993; 69:115-19.

$16 \mathrm{Li} \mathrm{J}$, Taylor B. Factors affecting uptake of measles, mumps, and rubella immunisation. BMF 1993;307:168-71

$17 \mathrm{Li} \mathrm{J}$, Taylor B. Immunisation uptake and family size. Health Trends 1993;25:16-19.

18 Tohani VK, Boyle G, Moore T. Haemophilus influenzae type $\mathrm{b}$ (Hib) vaccination and uptake predictors in type b (Hib) vaccination and uptake predictors in
Northern Ireland. Commun Dis Rep CDR Rev 1996;6:52-4.

$19 \mathrm{Li} \mathrm{J}$, Taylor B. Comparison of immunisation rates in general practice and child health clinics. BMF 1991;303:1035-8.

20 Nicoll A, Elliman D, Begg NT. Immunisation: causes of failure and strategies and tactics for success. BMF 1988;299: 808-12.

21 Szilagyi PG, Rodewald LE, Humiston SG, et al. Missed opportunities for childhood vaccinations in office practices and the effect on vaccination status. Pediatrics 1993;91:1-7.

22 Ferson MJ, Fitzsimmons G, Christie D, Woollett H. School health nurse interventions to increase immunisation uptake in school entrants. Public Health 1995;109:25-9.

23 Bedford HE, Masters JI, Kurtz Z. Immunisation status in inner London primary schools. Arch Dis Child 1992;67: 1288-91. 